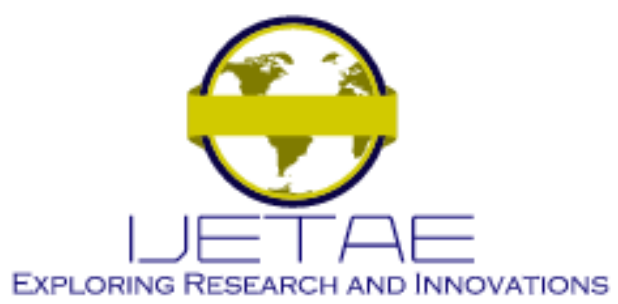

International Journal of Emerging Technology and Advanced Engineering

Website: www.ijetae.com (E-ISSN 2250-2459, Scopus Indexed, ISO 9001:2008 Certified Journal, Volume 11, Issue 10, October 2021)

Manuscript Received: 02 September 2021, Received in Revised form: 04 October 2021, Accepted: 15 October 2021

DOI: $10.46338 /$ ijetae1021_18

\title{
Performance Evaluation of Multilateration and Fingerprinting Method in Indoor Positioning System
}

\author{
Christian Alvin Setiabudi ${ }^{1}$, Gede Putra Kusuma ${ }^{2}$ \\ Computer Science Department, BINUS Graduate Program - Master of Computer Science, Bina Nusantara University, Jakarta, \\ Indonesia, 11480
}

\begin{abstract}
Indoor Positioning System has been one of the most attractive research after Bluetooth Low Energy (BLE) was introduced. This technology mainly used because of the reduction of material and energy cost over time that has huge impact compared to other technologies, which are more costly. Most recent research resolve around improving the accuracy of calculated position of the user by implementing different method to enable an indoor positioning system, and to remove any noises in the dataset. This paper objective is to compare some of the available methods that are used to enable Indoor Positioning System such as Fingerprinting, Multilateration, Trilateration, and Heron Bilateration. Since the performance of Fingerprinting is better compared to other methods, we combine Fingerprinting's offline phase with the other methods to create a hybrid method and compare the accuracy of predicted user's position. The experimental results show that the Fingerprinting and WKNN method outperform all other methods by resulting on $271.76 \mathrm{~cm}$ mean of error.
\end{abstract}

Keywords - Indoor Positioning System, Fingerprinting, Multilateration, Trilateration, Heron Bilateration.

\section{INTRODUCTION}

Positioning system has been used in various way. In real life, the positioning system is used to be a navigation system. This positioning system is categorized as Outdoor Positioning System and is mostly using GPS technology. Meanwhile Indoor Positioning System purpose is mainly to track a location inside a building, which GPS couldn't cover for it, because GPS technology lack line of sight inside a building and the signal will be fall off as it cross through solid objects like walls [1].

There are many researches that are conducted about Indoor Positioning System and many methods of calculating the user position are introduced. To enable and replace the GPS technology in indoor environment, we can replace it by using Wi-Fi, Infrared, Ultrasound, RFID and BLE.
Among these technologies, Wi-Fi and BLE are the most popular technology used in this research topic. According to [17], BLE has more advantage than Wi-Fi because of higher availability, lower power consumption, lower cost [3], and it is easy to setup/set the BLE [2]. But of course, there is a drawback in using this technology that we need to install many BLE because the range of the signal is not that wide compared to the Wi-Fi and also the attenuation of the signal is relatively large.

BLE is a transmitter with $2.4 \mathrm{GHz}$ radio wave frequency that is used to send a signal to the user (RSSI) and from that signal we can calculate the location of the user itself. BLE has 4.0 Bluetooth standard and has different spec compared to classic Bluetooth such as its application throughput is around $300 \mathrm{kbps}$, which is up to seven times smaller than then standard Bluetooth [4]. Also, the power needed for BLE is 100 times lower [4].

In previous research many researches are conducted on static user where user didn't move to collect RSSI data and later will be estimated. But in our experiment, user is constantly moving on a route. By constantly moving means we move on a constant velocity. Various indoor positioning method had been implemented, but mainly Fingerprinting and Trilateration are used frequently to solve this problem. In fingerprinting method, we can calculate the user location based on the signal strength. This method consists of two phases that are Offline and Online phases [18]. Offline phase used to store the signal strength from each beacon based on a grid or position in each reference point and stored in database [19]. Meanwhile online phase will calculate the position of the object by using the signal strength from each beacon that will be matched by previous data in Offline phase. To determine the position of the object that are some approaches such as Machine Learning algorithm. In Trilateration method the position will be calculated by estimating the distance of three beacon to the object. These distances will be used to calculate the position of the object. 


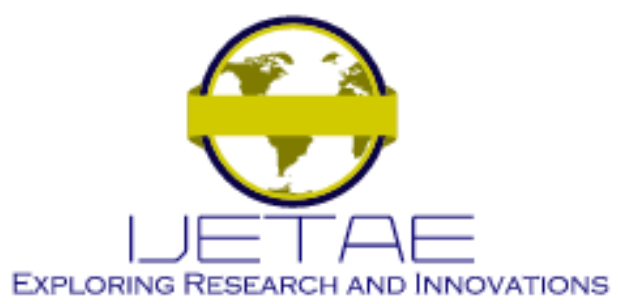

International Journal of Emerging Technology and Advanced Engineering

Website: www.ijetae.com (E-ISSN 2250-2459, Scopus Indexed, ISO 9001:2008 Certified Journal, Volume 11, Issue 10, October 2021)

There are also several improvement methods for trilateration such as Multilateration and Heron Bilateration. Multilateration is a widespread technique used to estimate the user location based on its distance measurement [5] which is the same as Trilateration. The main differences in these methods are the number of the BLE that are used to estimate the user position are mostly more than 3 BLE, meanwhile in trilateration we only use $3 \mathrm{BLE}$ to calculate the user position. Meanwhile, Heron Bilateration uses only 2 BLE to calculate the user position. But in this case, we use a Heron (triangle) behavior to calculate the user position refer to Figure 3. Heron Bilateration is created simply to simplify the computational complexity from three or more quadratic equations [6].

Based on paper [23] fingerprinting method accuracy will be better than trilateration because of fingerprinting already considering attenuation in the testbed or radiomap database creation process, which leads to a better accuracy in the signal strength data for calculation. In our research we want to compare the performance of fingerprinting $+\mathrm{WKNN}$ method with other method such as Multilateration, Trilateration, Heron Bilateration. Also, to see the performance of these method combined with fingerprinting we decided to create a hybrid method that implements fingerprinting offline phase to Multilateration, Trilateration, or Heron Bilateration method and see whether it improves the method or not.

\section{RELATED WORKS}

Indoor positioning system using BLE system had been experimented with various method as shown in Table 1. In paper [7] indoor positioning system are applied by using fingerprinting method combined with Weighted Centroid Localization. In this paper to train the data Gaussian filter are used to get the average of the RSSI data. The focus of this paper is to reduce the number of Reference Point used in fingerprinting localization process. The result is optimized but the cost is increased to train the data instead.

In paper [8] described some factor that could affect the performance of fingerprinting such as door, window, walls, number of AP (Access Point) used, number of RP (Reference Point) used, human body, and many more. This research is conducted using the Fingerprinting method and propagation model to estimate the distance. Fingerprinting is used because a high precision and low cost to be applied.
In paper [9] closest-a-priori location fingerprinting method are used to improve the accuracy of predicting the user location based on the BLE signal. To estimate the location of the data this research use K-NN and the average accuracy are around 1.8 meter, Paper [6] implements Heron Bilateration that are the improvement from trilateration by adding the concept of landmark to estimate the location from the beacon. This paper also proposed Drift Removal method using Kalman Filter to remove noise from the RSSI signal

There are also some researches that is applied to track a moving object location. In paper [10], the focus is to compare two different methods that is fingerprinting and trilateration that is applied to a moving object. In this paper the result is the accuracy of the estimated position are around 4 meters, because of the moving object that are hard to predict. This research use Wi-fi signal to get the distance from the object into each Access Point. In paper [11] Indoor positioning system are applied with Multilateration method to track a moving object. The research is being tested to track an object inside a moving container, the research result is 0.8 meter error for the estimated location

In paper [15] a comparison between Fingerprinting and Multilateration are compared. Fingerprinting that are used are the same with the common one that is divided into Online and Offline phase, in Offline phase the RSSI data are calibrated and stored into database to create a testbed, and in Online phase the data are compared to the testbed to determine the user location with the help of K-NN algorithm. For Multilateration, the distance estimation is calculated by using the signal strength (RSSI) based on 4-5 Access Point, which later Path Loss Exponent can be used to calculate the distance.

There are also some hybrid methods that are used. Paper [16] used a hybrid method to combine Wi-fi and Bluetooth technology there are three main aspects of this research: (1) avoid high error on positioning that are caused on Reference Point that are similar and hard to differentiate, (2) applying method to improve partition movement when user is out of detection zone of Bluetooth Hotspot, and (3) using three architectural for placement in computation workload. The method will find the best placement to place the Bluetooth Hotspot to get the optimal place. To get the position of the user fingerprinting method will be used by using wi-fi signal. This method results in improvement on accuracy for using the Bluetooth deployment. 


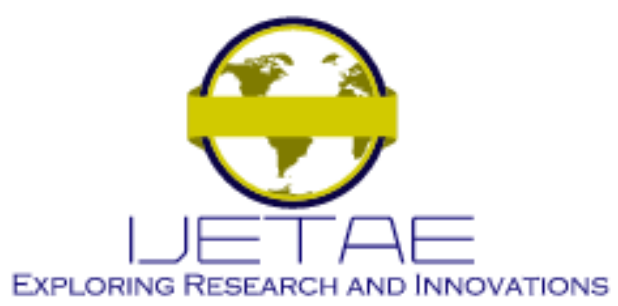

International Journal of Emerging Technology and Advanced Engineering

Website: www.ijetae.com (E-ISSN 2250-2459, Scopus Indexed, ISO 9001:2008 Certified Journal, Volume 11, Issue 10, October 2021)

From the previous work, the most used methods in this area of topic are fingerprinting and trilateration. Based on these two methods, this research will combine them into a hybrid method to see whether these two methods will give a better accuracy compared to the non-hybrid one.

TABLE I

PERFormance COMPARISON OF HYBRID AND NON-HYBRID METHODS

\begin{tabular}{|c|c|c|}
\hline Publication & Proposed Technique & Result \\
\hline$[7]$ & $\begin{array}{c}\text { Weighted Centroid } \\
\text { Localization }\end{array}$ & $\begin{array}{c}\text { Reference point } \\
\text { required are } \\
\text { reduced } 40 \%\end{array}$ \\
\hline$[8]$ & $\begin{array}{c}\text { Fingerprinting and } \\
\text { Propagation Model }\end{array}$ & $\begin{array}{c}\text { Method resulting } \\
\text { in high precision } \\
\text { and low cost }\end{array}$ \\
\hline$[9]$ & $\begin{array}{c}\text { Location } \\
\text { Fingerprinting }\end{array}$ & $\begin{array}{c}\text { More accurate, but } \\
\text { there is still some } \\
\text { error }\end{array}$ \\
\hline$[6]$ & Heron Bilateration & $\begin{array}{c}\text { More accurate } \\
\text { around } 0.5 \mathrm{~m}\end{array}$ \\
\hline$[11]$ & Multilateration & Error around $0.8 \mathrm{~m}$ \\
\hline
\end{tabular}

\section{INDOOR POSITIONING METHODS}

\section{A. Fingerprinting}

Fingerprinting is basically divided into two phases, offline and online phase. Offline phase is phase to learn RSSI signal strength in each of Reference Point. This phase output will be a test bed, or we can say Radio map Database consisting of all Reference Point with each of them have a RSSI data from each beacon (Figure 1). This phase task is mainly to collect fingerprinting data to be used as our model.

Online phase is phase to estimate the location of user. In this phase will be using localization algorithm and will be compared to the test bed that we get on the offline phase. In our research the sample will be taken with interval of 5 seconds. Then the sample data containing RSS value will be tracked by using Weighted Sum that will measured with Euclidean distance and then ranked using the K-nearest Neighbor, resulting a single value consisting of their coordinate $(\mathrm{x}, \mathrm{y})$.

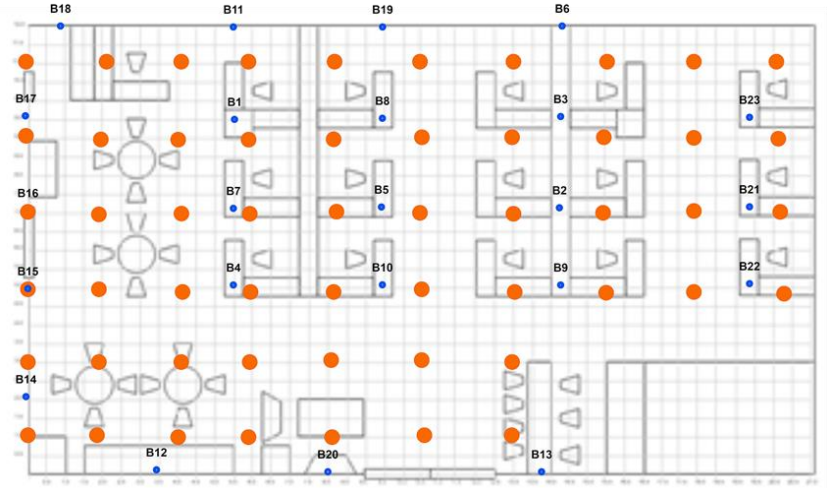

Figure 1 Reference Points of Radio Map

\section{B. Weighted Sum}

Weighted Sum are a method that is popular to rank a dataset [18]. This method is easy to use and the simplest method to be used. Weighted Sum model purpose was to estimate the position from the measured RSS. In this Research the steps of Weighted Sum are:

1. Calculate the distance $D$ between the measured RSS and the Reference Points RSS using Euclidean distance

$$
\mathrm{D}(\mathrm{mp}, \mathrm{rp})=\sqrt{\left(\sum_{\mathrm{i}=23}^{23}\left(\mathrm{RSS}_{\mathrm{i}}^{\mathrm{mp}}-\mathrm{RSS}_{\mathrm{i}}^{\mathrm{rp}}\right)\right.}
$$

2. Sort the distance in ascending order

3. Select $\mathrm{k}$ number of RP with the smallest distance from the measured RSS

4. Calculate the weight $W$ of each reference points by using (2)

$$
W_{i}=\frac{D_{i}}{\sum_{i=k}^{k} D_{i}}
$$

5. Calculate the predicted $\mathrm{x}$ and y coordinate using (3)

$$
\mathrm{x}=\sum_{\mathrm{i}=\mathrm{k}}^{\mathrm{k}}\left(W_{i} X_{i}^{r p}\right) \quad \text { and } \quad y=\sum_{i=k}^{k}\left(W_{i} y_{i}^{r p}\right)
$$




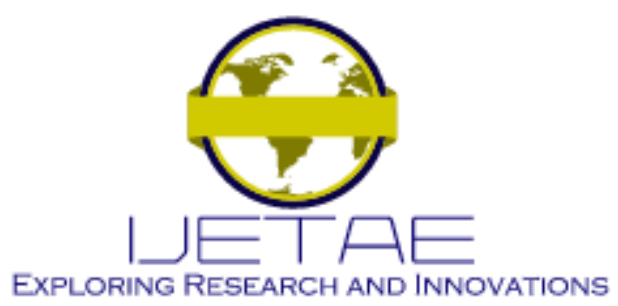

International Journal of Emerging Technology and Advanced Engineering

Website: www.ijetae.com (E-ISSN 2250-2459, Scopus Indexed, ISO 9001:2008 Certified Journal, Volume 11, Issue 10, October 2021)

\section{Trilateration and Multilateration}

Trilateration and Multilateration are a method to be used as location estimation [6], Trilateration will use 3 beacon to calculate the coordinate of the object meanwhile, as the name said Multilateration will use n-beacon to calculate the coordinate of the object $(\mathrm{x}, \mathrm{y})$. To use this method the main input are the distance from the beacon to the object $(D)$, and also beacon coordinate $\left(\mathrm{x}_{\mathrm{n}}, \mathrm{y}_{\mathrm{n}}\right)$. Later the equation (4) could be solved with help from Solution Algorithm such as LSQ (Least Square) method.

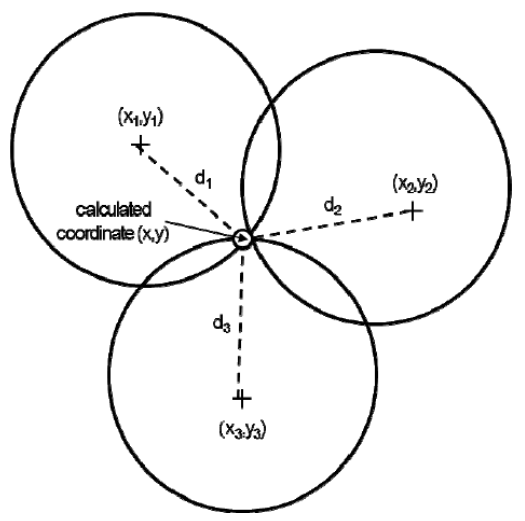

Figure 2 Trilateration

$$
\begin{gathered}
\left(x-x_{n}\right)^{2}+\left(y-y_{n}\right)^{2}=D_{n}^{2} \\
n=1, \ldots, 3
\end{gathered}
$$

To solve the equation, we need a solver algorithm. One of the popular solver algorithms is LSQ (Least Square) algorithm.

\section{Heron Bilateration}

Heron Bilateration are an improvement to existing trilateration method. This method simplifies the computational complex of three or more quadratics equation [6], by simplifying this then the effort to calculate the equation will be reduced. This method also proposed the Heron formula to help the location estimation based on a triangle behaviour where equation (5) and (8) is Triangle Area equation, with (6) is triangle semi perimeter equation. $\mathrm{D}_{\mathrm{Hn}}$ is the distance between the targeted reader and the reference tag. Meanwhile $b$ is distance between $y$ coordinate of two beacons. From this equation we can get the coordinate $\mathrm{x}$ from equation (9) and coordinate $\mathrm{y}$ from equation (12).

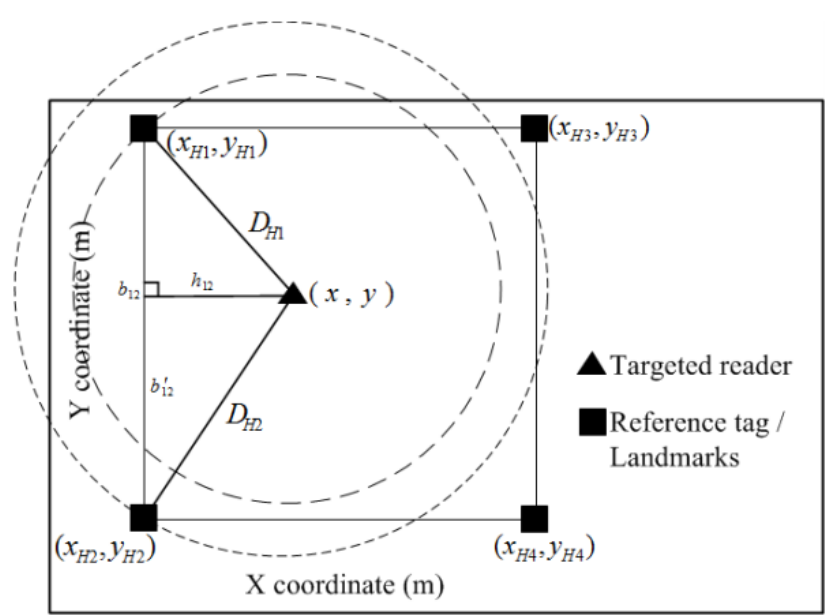

Figure 3 Heron Bilateration

$A=\sqrt{s\left(s-D_{H 1}\right)\left(s-D_{H 2}\right)\left(s-b_{12}\right)}$

$s=\frac{1}{2}\left(D_{H 1}+D_{H 2}+b_{12}\right)$

$b_{12}=\left|y_{H 1}-y_{H 2}\right|$

inside triangle $\left[\left(x_{H 1}, y_{H 1}\right),(x, y),\left(x_{H 2}, y_{H_{2}}\right)\right]$

$A=\frac{1}{2}\left(b_{12} h_{12}\right)$

$\mathrm{x}=\mathrm{x}_{\mathrm{H} 2}+\frac{2 \sqrt{\left(\mathrm{s}\left(\mathrm{s}-\mathrm{D}_{\mathrm{H} 1}\right)\left(\mathrm{s}-\mathrm{D}_{\mathrm{H} 2}\right)\left(\mathrm{s}-\mathrm{b}_{12}\right)\right)}}{\mathrm{b} 12}$

inside triangle $\left[\left(x_{H 1}, y_{H 1}\right),(x, y),\left(x_{H 2}, y_{H 2}\right)\right]$

$\mathbf{D}_{\mathrm{H} 2}^{2}=\mathbf{h}_{12}^{2}+\mathbf{b}_{12}^{\prime 2}$

$\mathrm{y}=\mathrm{y}_{\mathrm{H} 2}+\sqrt{\left(\mathrm{D}_{\mathrm{H} 2}^{2}\right)}-\mathbf{h}_{12}^{2}$

\section{E. Hybrid Method}

In this research, we also try to combine the behavior of fingerprinting Offline phase and Trilateration. In fingerprinting offline phase we collect the data of each RSSI from each beacon at each Reference Point. This data will be used to construct a test bed. The test bed will help to calculate the distance from reference point to the beacon. 


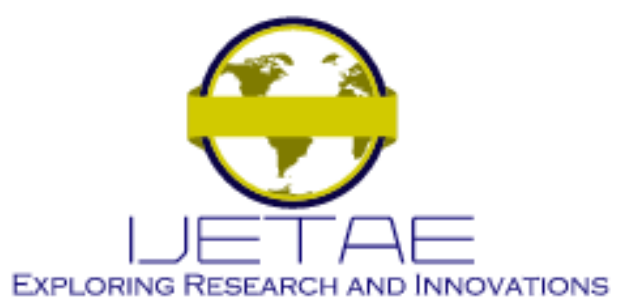

International Journal of Emerging Technology and Advanced Engineering Website: www.ijetae.com (E-ISSN 2250-2459, Scopus Indexed, ISO 9001:2008 Certified Journal, Volume 11, Issue 10, October 2021)

We also have the data of Reference Point coordinate. This data later will be used as the first step of the trilateration method which is distance estimation. The step of this hybrid method is illustrated in Figure 4.

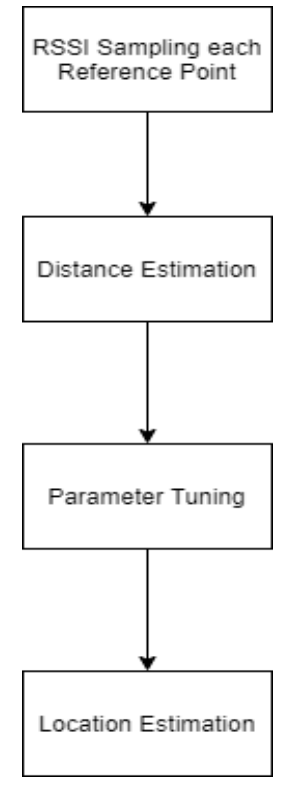

Figure 4 Hybrid Method Step

Distance estimation are a method that are supposed to calculate the distance from the beacon to the object by using the signal strength (RSSI). We modified this method to calculate the distance from the reference point to the object.

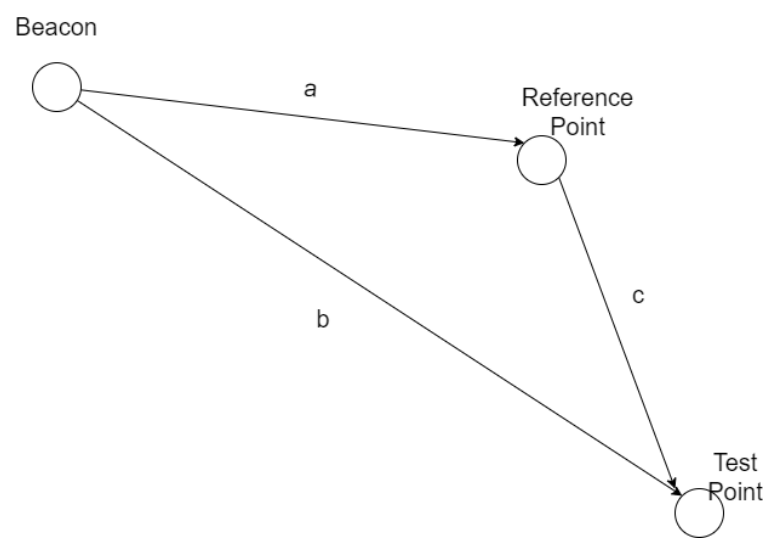

Figure 5 Distance from RP to TP
To get the distance between RP and the object we can subtract the distance between the object and beacon with the distance between RP and beacon shown in equation (14-16) where $p(d) d B m$ are the RSSI signal strength or $c=|b-a|$ in Figure 5. Later we will calculate the average of this calculated distance for $\mathrm{n}$ beacon that has stronger signal in each test point coordinates.

$$
\begin{aligned}
& p(d) d B m=p(d 0) d B m-10 n \log \left(\frac{d}{d 0}\right)+X d B m(14)
\end{aligned}
$$

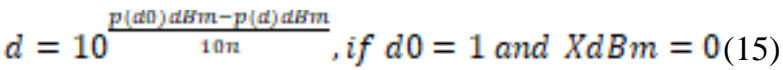

$$
\begin{aligned}
& d_{R P-T P}=\left|d_{T P-B L E}-d_{R P-B L E}\right| \\
& D=\frac{\sum_{i=1}^{n} d_{\mathcal{F P}}-\overline{T P}}{n}
\end{aligned}
$$

When calculating distance between Reference Point and Test Point (object/user), we will be doing parameter tuning where we switch the parameter and see the result of it. The parameter that we switch are d0 selection, and total of stronger signal beacon. The $\mathrm{d} 0$ selection that we used are $\mathrm{d} 0$ $=1$ meter, $\mathrm{d} 0=$ nearest RP from the beacon and $\mathrm{d} 0=$ nearest RP from TP as shown in Figure 6. For the total beacon used (n) are changed between 4,8 , and 12 beacon in equation (17). We simply will select the best accuracy distance from these parameter tuning later to be used in Location Estimation method.

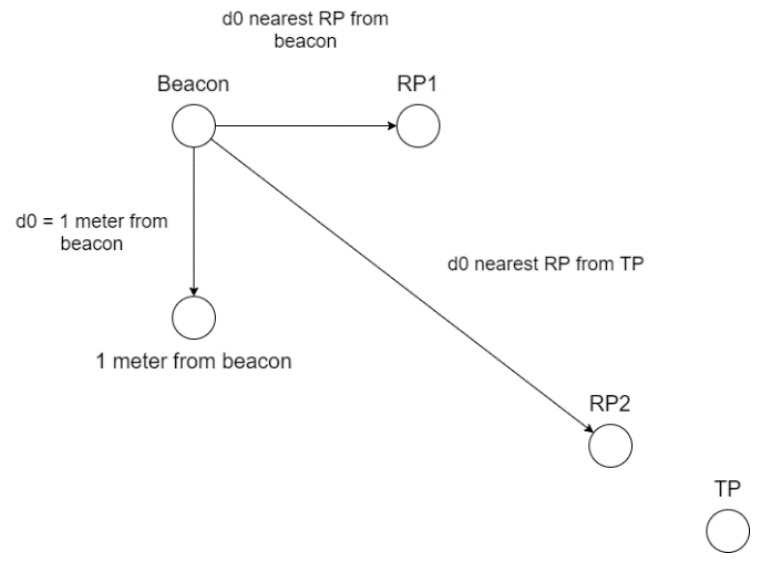

Figure 6 Distance Selection Method

The four nearest distance (from RP) that we get in each Test Point coordinate will be used as a next step that is called Location estimation. 


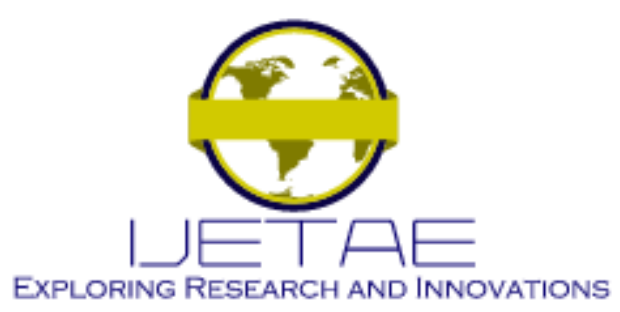

International Journal of Emerging Technology and Advanced Engineering

Website: www.ijetae.com (E-ISSN 2250-2459, Scopus Indexed, ISO 9001:2008 Certified Journal, Volume 11, Issue 10, October 2021)

Location estimation are a step to estimate the object's location by using the distance between the Test Point and Reference Point using equation (4). Later we switch the trilateration method with Multilateration or heron Bilateration method. So there will be three proposed Hybrid Method that are Fingerprinting and Multilateration/Trilateration/Heron Bilateration. To keep the number of distance used we implement combination rule so in trilateration and Heron Bilateration will still be using four nearest distance. In trilateration will be using $C_{\mathrm{a}}^{4}=4$ so there will be 4 estimated point, and for heron Bilateration will be using $C_{2}^{4}=6$ so there will be 6 estimated point. And then we simply calculate the average of it to get the final estimated point. All of these method will be compared to select the best method to calculate the location.

\section{EXPERIMENTS}

\section{A. Data Collection}

For system setup, the 23 beacon are configured with 0 $\mathrm{dBm}$ transmit power with interval 100 milliseconds. The beacons are deployed based on the location predefined before based on the blue dots in Figure 1. All beacons are deployed on the site $1.2 \mathrm{~m}$ height from the floor.

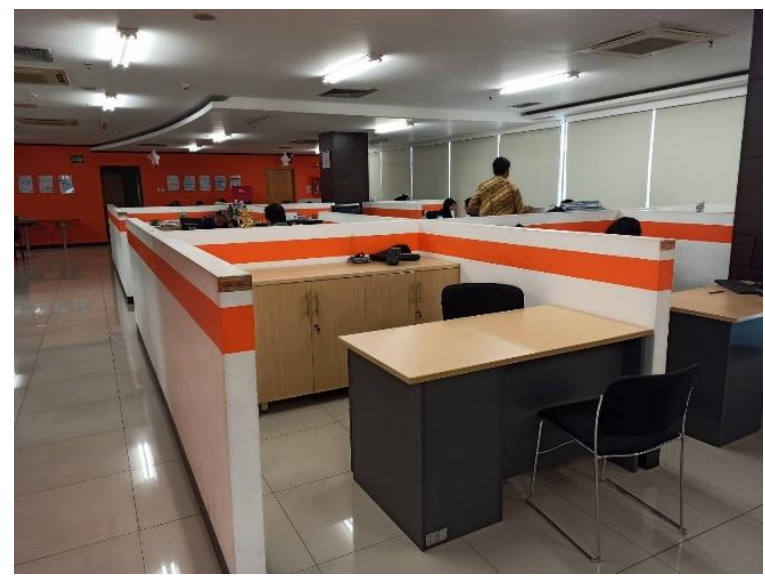

Figure 7 Office Room Condition
The test field environment is located on the 8th floor of Bina Nusantara University Kampus Anggrek, which is a lecturer office room with size $12 \mathrm{~m} \times 19 \mathrm{~m}$ (Figure 7), with many obstacles such as table, chair, and people in the room. Each Reference Point are placed with 2 meters gap each (orange dots in figure 1) with total of 54 reference point are defined in the radio map. Data collection are divided into two phase which are offline and online data. Offline data are used in offline phase of fingerprinting to collect the data based on each reference points and online data will be used to predict the user coordinate by using each methods. On each reference point we collect the RSSI data from each of the beacon with total of 100 samples data each reference point by using smartphone with specification in Table 2 , this process took around 3 minutes by standing in each of the reference point to sample the RSSI in reference point coordinate.

TABLE II

DEVICE SPECIFICATION

\begin{tabular}{|c|c|}
\hline \multicolumn{2}{|r|}{ Xiaomi Redmi Note 8} \\
\hline OS & Android 9.0 (Pie); MIUI 11 \\
\hline Chipset & Qualcomm SDM665 Snapdragon $665(11 \mathrm{~nm})$ \\
\hline $\mathrm{CPU}$ & Octa-core (4x2.0 GHz Kryo 260 Gold \& 4x1.8 GHz Kryo 260 Silver) \\
\hline GPU & Adreno 610 \\
\hline WLAN & Wi-Fi $802.11 \mathrm{a} / \mathrm{b} / \mathrm{g} / \mathrm{n} / \mathrm{ac}$, dual-band, Wi-Fi Direct, hotspot \\
\hline Bluetooth & $4.2, \mathrm{~A} 2 \mathrm{DP}, \mathrm{LE}$ \\
\hline GPS & Yes, with A-GPS, GLONASS, BDS \\
\hline
\end{tabular}

In order to collect the data from each beacon in each reference point, the application needs to wait until each beacon respond to our smartphone device to start the scan. After the scan started the data will be saved until it reach the maximum number (100 in this case). To minimize and avoid repetitive value and zero value we add and interval of 1 second per scan. The result will be used as radio map dataset to be used to determine the distance for testing route. There is also an additional data for our parameter tuning step which needs the RSSI gathered 1 meter from each beacon. The data collection step and setup are also the same as the offline data collection. 


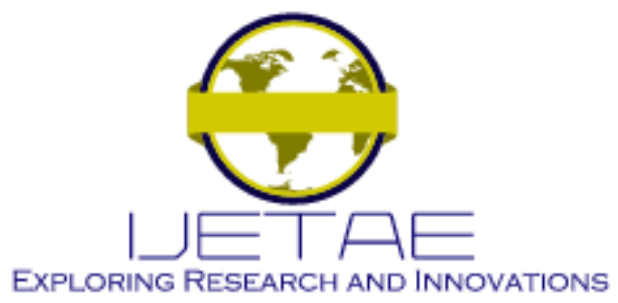

International Journal of Emerging Technology and Advanced Engineering

Website: www.ijetae.com (E-ISSN 2250-2459, Scopus Indexed, ISO 9001:2008 Certified Journal, Volume 11, Issue 10, October 2021)

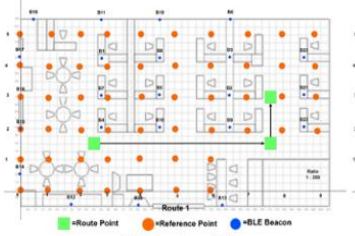

(Route 1)

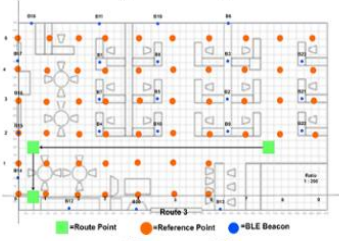

(Route 3)

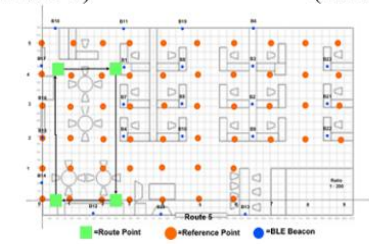

(Route 5)

Figure 8 List of Route

Meanwhile online data are used for online phase or can be called as experimental data. Testing route (Figure 8) are defined between reference points, with constraint that the route should be inside the reference point to maximize the data that are being collected. If the route is outside the reference point there is a possibility that the signal will not be delivered correctly. In each route we make sure that the velocity when collecting the data is stable, this because we want it to not too slow or too fast. All route experiment in this paper is taken with $5 \mathrm{~s}$ scan interval and constant velocity of $20 \mathrm{~cm} / \mathrm{s}$.

\section{B. Experimental Design}

After collecting all the data, the experiment begins by creating the radio map database (Offline phase of Fingerprinting) by using the offline data. The radio map is constructed by calculating the mean of all the data collected in each reference points. The mean of the data would be used as RSSI representative for each reference point.

The online data are divided into 2 dataset which are parameter tuning dataset consisting of route $1,2,3$ and testing dataset consisting of routes 4 and 5 as shown in Figure 8. The parameter tuning is used to select which parameter setup are resulting the best distance that is the closest to the ground truth.
There are several combinations of parameter that we want to measure which is $\mathrm{d} 0$ selection and total beacon.

These parameter tuning are conducted by using the Distance estimation phase on Trilateration method. D0 selection parameter are used to select the best $\mathrm{d} 0$ variable in equation 14 , we used three different $\mathrm{d} 0$ which is 1 meter from beacon, RP nearest to TP, and RP nearest to beacon. In each route data there will be 23 RSSI data from each beacon, but since we won't be using all those data ideally, we want to select the number of the beacon (n) that are used to measure the distance in equation 17. So, in order to select the number of beacons are used we select between 4, 8, 12 beacon that sorted by the strongest RSSI in each route data. The combination of these two parameters will be conducted on route 1,2 , and 3 to see which combination are the best to be used for the testing.

The testing data are used by applying the selected combination of parameter when calculating the distance on the distance estimation phase. This distance will be used as the input for the location estimation phase. The location estimation phase will be conducted by using each of the method that we are evaluating in this research, which are trilateration (Equation (4)), heron Bilateration (Equation (5) - (12)), Multilateration (Equation (4)), and hybrid method. The parameter for total beacon can also be applied on fingerprinting + WKNN method for selecting the total of strongest RSSI beacon used.

The experiment then continues by evaluating the performance of the calculated coordinate for each method by calculating the error which are catered by using Euclidean distance to see the distance between the calculated coordinate and ground truth. This error then will be used to measure the performance evaluation by finding mean, min, max, median, and $90^{\text {th }}$ percentile of the error. The lower the mean of error resulted means that method are giving a good result. Another evaluation method we applied in this experiment are by using the Accuracy percentage for parameter tuning phase by calculating the correct prediction of the 4 nearest reference point in each route data. The higher the accuracy means that the parameter given can predict the 4 nearest reference point in each route data.

\section{Experimental Results}

The experiment was conducted in 3 routes for parameter tuning and 2 routes for testing. Each route is gathered around 3-5 minutes with around 20-50 row of data and an interval of $5 \mathrm{sec}$ to avoid data loss. 


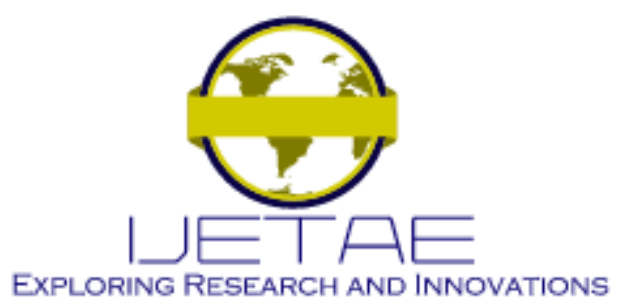

International Journal of Emerging Technology and Advanced Engineering

Website: www.ijetae.com (E-ISSN 2250-2459, Scopus Indexed, ISO 9001:2008 Certified Journal, Volume 11, Issue 10, October 2021)

The data of each route then will be processed to estimate the user position ( $\mathrm{x}, \mathrm{y})$ by using each proposed method and will be compared to ground truth.

For parameter tuning we used route number 1,2 , and 3. We compare the distance estimation result by comparing the calculated distance to the ground truth and compare the number of nearest RP predicted and ground truth.

TABLE III

Parameter Tuning Table

\begin{tabular}{|c|c|c|c|c|}
\hline $\begin{array}{c}\text { D0 } \\
\text { selection }\end{array}$ & $\begin{array}{c}\text { Total } \\
\text { Beacon }\end{array}$ & $\begin{array}{c}\text { Mean } \\
\text { of } \\
\text { Error } \\
\text { (m) }\end{array}$ & $\begin{array}{c}\text { Accuracy } \\
\text { Percentage }\end{array}$ & $\begin{array}{c}\text { D0 } \\
\text { selection }\end{array}$ \\
\hline 1 meter & 8 beacons & 1.82 & $35.9 \%$ & 1 meter \\
\hline $\begin{array}{c}\text { RP } \\
\text { nearest } \\
\text { to } \mathbf{T P}\end{array}$ & 8 beacons & 1.92 & $27.7 \%$ & $\begin{array}{c}\mathrm{RP} \\
\text { nearest } \\
\text { to } \mathrm{TP}\end{array}$ \\
\hline $\begin{array}{c}\mathbf{R P} \\
\text { nearest } \\
\text { to } \\
\text { beacon }\end{array}$ & 8 beacons & 1.62 & $22.4 \%$ & $\begin{array}{c}\mathrm{RP} \\
\text { nearest } \\
\text { to } \\
\text { beacon }\end{array}$ \\
\hline 1 meter & 4 beacons & 2.14 & $24.35 \%$ & 1 meter \\
\hline $\begin{array}{c}\mathrm{RP} \\
\text { nearest } \\
\text { to } \mathrm{TP}\end{array}$ & 4 beacons & 2.29 & $19.84 \%$ & $\begin{array}{c}\mathrm{RP} \\
\text { nearest } \\
\text { to } \mathrm{TP}\end{array}$ \\
\hline $\begin{array}{c}\mathbf{R P} \\
\text { nearest } \\
\text { to } \\
\text { beacon }\end{array}$ & 4 beacons & 1.98 & $17.18 \%$ & $\begin{array}{c}\mathrm{RP} \\
\text { nearest } \\
\text { to } \\
\text { beacon }\end{array}$ \\
\hline 1 meter & 12 beacons & 1.51 & $33.98 \%$ & 1 meter \\
\hline $\begin{array}{c}\text { RP } \\
\text { nearest } \\
\text { to } \mathbf{T P}\end{array}$ & 12 beacons & 2.13 & $37.69 \%$ & $\begin{array}{c}\mathrm{RP} \\
\text { nearest } \\
\text { to } \mathrm{TP}\end{array}$ \\
\hline $\begin{array}{c}\mathbf{R P} \\
\text { nearest } \\
\text { to } \\
\text { beacon }\end{array}$ & 12 beacons & 2.94 & $24.47 \%$ & $\begin{array}{c}\mathrm{RP} \\
\text { nearest } \\
\text { to } \\
\text { beacon }\end{array}$ \\
\hline
\end{tabular}

From the parameter tuning result in Table 3, we can see that the mean of error is around 1-2 meter, and the accuracy of predicted RP are below 50\%. So, we decided to select the best $\mathrm{d} 0$ selection method that is using $\mathrm{d} 0=1 \mathrm{~m}$ and the total beacon that we used are 12 beacons. Based on the result we continue the implementation by doing the Location Estimation by using the route number 4 and 5 .
Also, we used the same amount of beacon (12 beacon) for Fingerprinting + WKNN method.

TABLE IV

PERFORMANCE COMPARISON OF STANDARD METHOD

\begin{tabular}{|c|c|}
\hline Method & Mean of Error $(\mathbf{c m})$ \\
\hline Multilateration & 328.76 \\
\hline Trilateration & 331.59 \\
\hline Heron Bilateration & 337.09 \\
\hline Fingerprinting + WKNN & 271.76 \\
\hline
\end{tabular}

In Table 4 we can see the performance of each method that we implement. We can see that the error rate for Fingerprinting + WKNN outperform the other method such as Multilateration, Trilateration, and Heron Bilateration. Then we try to implement the behavior of the fingerprinting offline phase to create the hybrid method.

TABLE V

Hybrid Method Performance SUMmary

\begin{tabular}{|c|c|c|c|c|c|c|}
\hline Route and Method & \multicolumn{5}{|c|}{ Performance } \\
\cline { 3 - 7 } & $\begin{array}{c}\text { Mean } \\
\text { of } \\
\text { error } \\
(\mathbf{c m})\end{array}$ & $\begin{array}{c}\text { Min } \\
\text { of } \\
\text { error } \\
(\mathbf{c m})\end{array}$ & $\begin{array}{c}\text { Max } \\
\text { of } \\
\text { error } \\
(\mathbf{c m})\end{array}$ & $\begin{array}{c}\text { Median } \\
\text { of error } \\
(\mathbf{c m})\end{array}$ & $\begin{array}{c}\mathbf{9 0}^{\text {th }} \\
\text { Percentile } \\
\text { of error } \\
(\mathbf{c m})\end{array}$ \\
\hline Route 4 & $\begin{array}{c}\text { Multilater } \\
\text { ation }\end{array}$ & 371. & 105 & 818 & 391.3 & 536.99 \\
& 64 & .89 & .01 & 7 & \\
\hline Route 5 & Multilater & 324. & 86. & 713 & 282.2 & 594.92 \\
& ation & 91 & 508 & .82 & 3 & \\
\hline Route 4 & $\begin{array}{c}\text { Trilaterati } \\
\text { on }\end{array}$ & 374. & 104 & 778 & 399.9 & 577.92 \\
& on & .46 & .86 & 3 & \\
\hline Route 5 & Trilaterati & 324. & 86. & 713 & 282.2 & 594.91 \\
& on & 87 & 50 & .78 & 1 & \\
\hline Route 4 & Heron & 378. & 145 & 705 & 366.6 & 588.52 \\
& Bilaterati & 61 & .95 & .12 & 4 & \\
& on & & & & & \\
\hline Route 5 & Heron & 346. & 103 & 722 & 322.9 & 624.02 \\
& Bilaterati & 79 & .97 & .45 & 8 & \\
& on & & & & & \\
\hline
\end{tabular}

The result of the hybrid method is shown at Table 5 for route 4 and 5 respectively. Our mean of error for the hybrid method are around 3.5 meter. This result then will be compared our method to each non hybrid method respectively in Table 6 . 


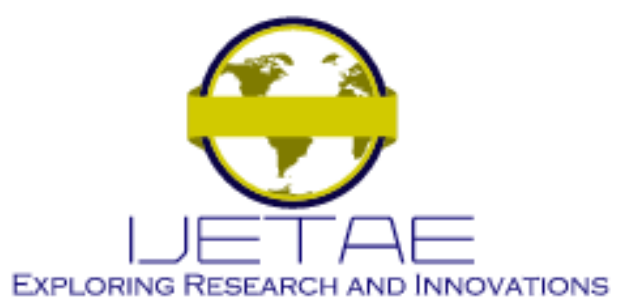

International Journal of Emerging Technology and Advanced Engineering

Website: www.ijetae.com (E-ISSN 2250-2459, Scopus Indexed, ISO 9001:2008 Certified Journal, Volume 11, Issue 10, October 2021)

TABLE VI

PERFormanCE COMParison Hybrid AND NON-Hybrid

\begin{tabular}{|c|c|c|}
\hline Method & $\begin{array}{c}\text { Mean of Error } \\
\text { (Hybrid) }(\mathbf{c m})\end{array}$ & $\begin{array}{c}\text { Mean of Error } \\
\text { (Non-Hybrid) } \\
(\mathbf{c m})\end{array}$ \\
\hline Multilateration & 348.28 & 328.76 \\
\hline Trilateration & 349.46 & 331.59 \\
\hline $\begin{array}{c}\text { Heron } \\
\text { Bilateration }\end{array}$ & 362.71 & 337.09 \\
\hline $\begin{array}{c}\text { Fingerprinting + } \\
\text { WKNN }\end{array}$ & - & 271.76 \\
\hline
\end{tabular}

We analyze that our hybrid method performance is slightly worse than the non-hybrid method (around $20 \mathrm{~cm}$ difference). Because the performance is still $\pm 3 \mathrm{~m}$, we also compare this method to Fingerprinting + WKNN by using the same setup. The result of Fingerprinting + WKNN are showing a better result than the other methods and it is also stated in [23] that fingerprinting method are better than trilateration because of fingerprinting already considering attenuation in the testbed or radiomap database creation process, which leads to a better accuracy in the signal strength data for calculation. In addition to it we also want to see the performance of our methods that are using Average of Combination of 4 nearest RP versus only using 2/3 nearest RP.

TABLE VII

NUMBER OF RP PERFORMANCE COMPARISON

\begin{tabular}{|c|c|c|}
\hline Method & $\begin{array}{c}\text { Mean of Error } \\
\text { (Proposed } \\
\text { Method) } \mathbf{( c m )}\end{array}$ & $\begin{array}{c}\text { Mean of Error } \\
(\mathbf{2 / 3} \text { nearest RP) } \\
(\mathbf{c m})\end{array}$ \\
\hline Trilateration & 349.46 & 370.98 \\
\hline $\begin{array}{c}\text { Heron } \\
\text { Bilateration }\end{array}$ & 362.71 & 450.02 \\
\hline
\end{tabular}

The results in Table 7 show that the average of combination of 4 nearest RP are better than only using $2 / 3$ nearest RP. The big difference for our hybrid method is probably because of the error rate from the distance estimation process that could be considered high $( \pm 2 \mathrm{~m})$. Also, we believe that the error is high because of we capture the route data while moving and many other people and obstacle are in the office room that is quite big in size (12 m x $19 \mathrm{~m})$.

\section{CONCLUSION \& FUTURE WORKS}

We have compared existing method for indoor positioning method for tracking people while moving. Based on our result we concluded that the performance of fingerprinting method is resulting a better error rate than the other. We also try to combine the behavior of Fingerprinting to other method, but the hybrid method didn't get a better result. By testing it while the user is moving, we realize that we need some time before we can start the testing, this probably because the size of our room that is considered big and this factor could be the reason why there will be some noises in the RSSI data that we get, and of course we are positive that our method will give a better result for static data.

\section{REFERENCES}

[1] R.F. Brena, J.P. García-Vázquez, C.E. Galván-Tejada, D. MuñozRodriguez, C. Vargas-Rosales, J. Fangmeyer, "Evolution of Indoor Positioning Technologies: A Survey," Journal of Sensors, 2017(March), 2017, doi:10.1155/2017/2630413.

[2] A.A. Kalbandhe, S.C. Patil, "Indoor Positioning System based on Bluetooth Low Energy," 2016 International Conference on Computing, Analytics and Security Trends (CAST), (December), 451-455, 2016.

[3] Z. Ma, S. Poslad, J. Bigham, X. Zhang, L. Men, "A BLE RSSI ranking based indoor positioning system for generic smartphones," Wireless Telecommunications Symposium, (February 2019), 2017, doi:10.1109/WTS.2017.7943542.

[4] M. Ji, J. Kim, J. Jeon, Y. Cho, "Analysis of positioning accuracy corresponding to the number of BLE beacons in indoor positioning system," International Conference on Advanced Communication Technology, ICACT, 2015-August, 92-95, 2015, doi:10.1109/ICACT.2015.7224764

[5] A.C. Eyng, O.K. Rayel, E. Oroski, J.L. Rebelatto, "Kalman Filtering-Aided Hybrid Indoor Positioning System with Fingerprinting and Multilateration," IEEE Vehicular Technology Conference, 2020-May, 3-7, 2020, doi:10.1109/VTC2020Spring48590.2020.9129422.

[6] C.H. Huang, L.H. Lee, C.C. Ho, L.L. Wu, Z.H. Lai, "Real-time RFID indoor positioning system based on kalman-filter drift removal and heron-bilateration location estimation," IEEE Transactions on Instrumentation and Measurement, 64(3), 728-739, 2015, doi:10.1109/TIM.2014.2347691.

[7] S. Subedi, J.Y. Pyun, "Practical Fingerprinting Localization for Indoor Positioning System by Using Beacons," Journal of Sensors, 2017, 2017, doi:10.1155/2017/9742170.

[8] S. Xia, Y. Liu, G. Yuan, M. Zhu, Z. Wang, Indoor fingerprint positioning based on Wi-Fi: An overview, ISPRS International Journal of Geo-Information, 2017, doi:10.3390/ijgi6050135.

[9] Y.C. Pu, P.C. You, "Indoor positioning system based on BLE location fingerprinting with classification approach," Applied Mathematical Modelling, 2018, doi:10.1016/j.apm.2018.06.031. 


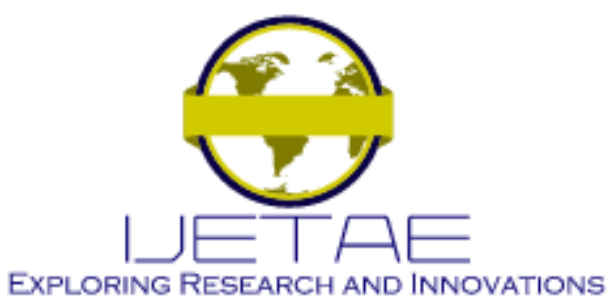

International Journal of Emerging Technology and Advanced Engineering

Website: www.ijetae.com (E-ISSN 2250-2459, Scopus Indexed, ISO 9001:2008 Certified Journal, Volume 11, Issue 10, October 2021)

[10] E. Mok, G. Retscher, "Location determination using wifi fingerprinting versus wifi trilateration," Journal of Location Based Services, 1(2), 145-159, 2007, doi:10.1080/17489720701781905.

[11] A. Wessels, X. Wang, R. Laur, W. Lang, "Dynamic indoor localization using multilateration with RSSI in wireless sensor networks for transport logistics," Procedia Engineering, 5, 220-223, 2010, doi:10.1016/j.proeng.2010.09.087.

[12] A. Mukhopadhyay, A. Mallisscry, "TELIL: A Trilateration and Edge Learning based Indoor Localization Technique for Emergency Scenarios," in 2018 International Conference on Advances in Computing, Communications and Informatics, ICACCI 2018, 2018, doi:10.1109/ICACCI.2018.8554587.

[13] Y. Lin, Y. Fang, W. Su, "A Hybrid Indoor Positioning System Design based on BLE," 2(10), 31-38, 2018.

[14] P. Torteeka, X. Chundi, Y. Dongkai, "Hybrid technique for indoor positioning system based on Wi-Fi received signal strength indication," IPIN 2014 - 2014 International Conference on Indoor Positioning and Indoor Navigation, (October), 48-57, 2014, doi:10.1109/IPIN.2014.7275467.

[15] M. Al Shayokh, "Experimental Performance Analysis and Improvement Techniques for RSSI Based Indoor Localization: RF Fingerprinting and RF Multilateration," Communications, 2(2), 15, 2014, doi:10.11648/j.com.20140202.11.

[16] A. Baniukevic, C.S. Jensen, H. Lu, "Hybrid indoor positioning with Wi-Fi and Bluetooth: Architecture and performance," in Proceedings - IEEE International Conference on Mobile Data Management, 2013, doi:10.1109/MDM.2013.30.

[17] A. Lindemann, B. Schnor, J. Sohre, P. Vogel, "Indoor positioning: A comparison of WiFi and Bluetooth Low Energy for region monitoring," HEALTHINF 2016 - 9th International Conference on Health Informatics, Proceedings; Part of 9th International Joint Conference on Biomedical Engineering Systems and Technologies, BIOSTEC 2016, 5(Biostec), 314-321, 2016, doi: $10.5220 / 0005704603140321$.
[18] Setiabudi, Christian. (2020). Indoor Positioning System Using BLE for Tracking Dynamic User Positions. International Journal of Emerging Trends in Engineering Research. 8. 455-463. 10.30534/ijeter/2020/33822020.

[19] H.S. Gang, J.Y. Pyun, "A smartphone indoor positioning system using hybrid localization technology," Energies, 12(19), 1-20, 2019, doi:10.3390/en12193702.

[20] J. Kwon, B. Dundar, P. Varaiya, "Hybrid algorithm for indoor positioning using wireless LAN," in IEEE Vehicular Technology Conference, 2004, doi:10.1109/vetecf.2004.1404967.

[21] A. Madhavapeddy, A. Tse, "A study of bluetooth propagation using accurate indoor location mapping," Lecture Notes in Computer Science (Including Subseries Lecture Notes in Artificial Intelligence and Lecture Notes in Bioinformatics), 3660 LNCS, 105-122, 2005.

[22] T. Wei, S. Bell, "Indoor localization method comparison: Fingerprinting and Trilateration algorithm Background and Relevance," University of Saskatchewan, 2010, doi:10.1080/17489720701781905.

[23] Y. Zhuang, J. Yang, Y. Li, L. Qi, N. El-Sheimy, "Smartphone-based indoor localization with bluetooth low energy beacons," Sensors (Switzerland), 16(5), 1-20, 2016, doi:10.3390/s16050596.

[24] M.E. Rusli, M. Ali, N. Jamil, M.M. Din, “An Improved Indoor Positioning Algorithm Based on RSSI-Trilateration Technique for Internet of Things (IOT)," Proceedings - 6th International Conference on Computer and Communication Engineering: Innovative Technologies to Serve Humanity, ICCCE 2016, 72-77, 2016, doi:10.1109/ICCCE.2016.28. 